\title{
PELATIHAN KOMUNIKASI INTERPERSONAL UNTUK MENGURANGI RASA MALU
}

\section{INTERPERSONAL COMMUNICATION TRAINING TO REDUCE SHYNESS}

\author{
Nandhini H. Anggarasari \\ RA. Retno Kumolohadi \\ Fakultas Psikologi dan IImu Sosial Budaya Universitas Islam Indonesia Yogyakarta \\ E-mail: kumolohadiretno@yahoo.com
}

\begin{abstract}
This study aims is to determine the effectiveness of interpersonal communication training to reduce the sense of shyness. The participants were 12 students aged 19 to 25 years, divided into experimental group and control group. The shyness was measured by scale of shyness based on the symptomsymptom Writer shyness presented by Henderson and Zimbardo (1998). This research used pretestposttest control group design. Mann Whitney test used to analyze the data. The result shows that there's gained score difference between Pretest and posttest experiment and control groups, with z value $=-2.656$ and $p=0,008(p<0,05)$. Thus, interpersonal communication training proved can reduce the sense of shyness.
\end{abstract}

Key words: effectiveness of training, embarrassment (shyness), interpersonal communication.

\begin{abstract}
ABSTRAK
Penelitian ini bertujuan untuk mengetahui efektivitas pelatihan komunikasi interpersonal dalam mengurangi rasa malu. Para peserta adalah 12 siswa berusia 19 sampai 25 tahun, dibagi menjadi kelompok eksperimen dan kelompok kontrol. Rasa malu ini diukur dengan skala rasa malu berdasarkan pada simtom rasa malu yang dikemukakan oleh Henderson dan Zimbardo (1998). Penelitian ini menggunakan pretest-posttest control group design. Uji Mann Whitney digunakan untuk menganalisis data. Hasilnya menunjukkan bahwa terdapat perbedaan gain skor antara Prates dan pascates kelompok eksperimen dan kelompok kontrol, dengan nilai $z=-2,656$ dan $p=0,008$ ( $p$ $<0,05)$. Dengan demikian, komunikasi interpersonal pelatihan terbukti dapat mengurangi rasa malu.
\end{abstract}

Kata kunci: efektivitas pelatihan, malu (rasa malu), komunikasi interpersonal 
Rasa malu terdiri atas tiga jenis, yaitu malu-malu dalam berbahasa, malu karena segan, dan malu karena aib. Malu-malu dalam berbahasa timbul apabila seseorang berhadapan dengan orang yang dihormati. Perasaan malu ini biasanya bertujuan agar tidak sampai menyakiti hati orang lain. Malu karena segan timbul saat seseorang tidak biasa melakukan pekerjaan tertentu sehingga timbul keadaan yang janggal. Misalnya seseorang yang merasa segan untuk bertutur kata pada orang yang tidak dikenali, lebih-lebih jika dia tidak terbiasa bertutur kata dengan orang asing. Rasa malu karena aib biasanya timbul apabila seseorang menyadari bahwa dirinya telah melakukan dosa dan perbuatannya telah diketahui oleh masyarakat luas. Perasaan aib ini sangat terkait dengan penghinaan. Orang yang merasa aib mungkin akan melakukan tindakan yang ekstrim seperti membunuh diri.

Rasa malu diartikan sebagai tanda harga diri, karena seseorang dapat dikatakan memiliki harga diri apabila dia memiliki rasa malu. Rasa malu merupakan sesuatu yang sehat karena dapat mendorong seseorang untuk menjaga sikap dan harga dirinya. Perasaan malu sangat penting dipupuk dalam masyarakat, karena rasa malu bisa menjadi benteng agar tidak melakukan sesuatu yang dianggap menyeleweng dan melanggar norma-norma dalam masyarakat. Menurut Zimbardo (1997), rasa malu (shyness) merupakan pengalaman biasa. Adakalanya seseorang merasa malu di depan umum karena mencemaskan bagaimana dapat dekat atau bertemu dengan orang lain, atau malu secara pribadi karena memfokuskan dan merasakan tentang diri sendiri. Rasa malu memiliki hal yang positif dan kadang bukan merupakan masalah yang berarti. Rasa malu dapat membantu orang pemalu untuk menghindari konflik atau mengintimidasi orang lain dan memberikan perubahan untuk bertahan, menggambarkan tentang situasi dan mengobservasi orang lain dalam lingkungan, dan dapat memberikan kesan sebagai orang yang pandai, rendah hati, atau sederhana dan bijaksana.

Rasa malu diartikan sebagai fungsi kawanan sosial. Rasa malu merupakan satu perasaan negatif yang timbul karena melakukan perbuatan yang tidak senonoh. Dalam budaya Melayu, seseorang yang menanggung malu akibat perbuatannya, tidak hanya ditanggung oleh dia sendiri, tapi juga oleh keluarganya. Hal ini dikarenakan masyarakat menganggap bahwa seseorang itu masih terikat pada keluarganya. Misalnya, seorang anak menyebabkan orang tuanya malu karena anak tersebut mencuri. Hal ini sama saja dengan "mencoreng arang di muka ibu bapak". Hal itu akan memengaruhi bagaimana sosialisasi anggota keluarga yang lainnya.

Rasa malu dapat muncul dalam lingkungan keluarga. Keluarga adalah lingkungan terdekat dan paling awal yang memberikan andil yang cukup 
besar dalam perkembangan seseorang. Perkembangan individu menurut Erikson (Monks, Knoers, \& Haditono, 2004) dalam stadium maskuler umur anak kecil lebih menekankan pada komponen otonomi versus rasa malu dan ragu-ragu. Bila keadilan dan kebijaksanaan tidak diterapkan, maka akan menimbulkan dampak di kemudian hari, yaitu kurangnya rasa kontrol dan tidak adanya kemauan yang kuat. Dampak ini akan terlihat ketika seseorang masuk tahap dewasa muda.

Dari wawancara pendahuluan pada beberapa mahasiswa psikologi yang peneliti temui, diketahui ada seorang mahasiswa yang memiliki rasa malu yang besar dalam bersosialisasi dan merasa tidak nyaman bila berada di tempat asing. Hal ini disebabkan adanya dorongan yang besar dari ibunya untuk lebih bersikap perfect dalam segala hal, sehingga dia menjadi canggung dan takut salah untuk melakukan sesuatu, dan akhirnya malu untuk bersosialisasi. Padahal, dalam masa-masa ini, individu dituntut untuk dapat bersosialisasi dengan orang lain dan membina hubungan dengan lawan jenis.

Ada juga individu yang menjadi malu dan ragu untuk melakukan sesuatu akibat dari kurang kompaknya orang tua dalam mendidik ketika dia masih kanakkanak. Misalnya cara ayah merawat pakaian berbeda dengan cara ibu merawat pakaian, dan dia tidak diberi kebebasan untuk memilih. Ketika dia menggunakan cara ayah, sang ibu marah. Ketika dia menggunakan cara ibu, ayah marah. Hal itu membuat dia menjadi bingung dan ragu. Akibatnya dalam bersosialisasi pun ia menjadi ragu, takut salah dan malu bila mendapatkan respon yang negatif dari orang lain.

Dalam lingkungan kehidupan, seseorang dapat berinteraksi dengan orang lain dan menghasilkan beraneka ragam hubungan. Ada permusuhan, pertemanan biasa, persahabatan, atau bahkan percintaan. Orang yang paling dekat dengan individu dan memberikan peran yang besar selain dalam lingkungan keluarga adalah sahabat. Dalam penelitian yang dilakukan oleh Fordham dan Stevenson-Hinde (1999) ditemukan bahwa kualitas persahabatan dapat membantu orang yang pemalu dalam mengatasi masalahnya, meningkatkan harga diri, dan mengurangi rasa kesepian dalam dirinya.

Pada sisi sosial, rasa malu timbul apabila individu tidak dapat lebih perfect dalam bersikap. Bila apa yang terjadi tidak seperti yang dibayangkan dan jauh dari harapan, maka hal ini membuat individu menjadi malu. Namun, malu dapat diatasi, salah satunya dengan bersikap terbuka dan jujur pada orang lain. Hal ini terjadi pada Bams Reguna Bukit, vokalis Samsons. Bams merasa malu karena penampilannya di atas panggung masih belum sesuai dengan yang dia harapkan. Baginya performance itu penting, dan dia 
harus menghadapi audience yang tidak sedikit. Dia mengatasi malunya dengan bersikap jujur dan terbuka dengan apa yang dia rasakan, dan menurutnya kejujuran itu membuat dia lebih percaya diri (www.kaltimpost.web.id).

Rasa malu karena khawatir orang lain menilai negatif tentang diri individu merupakan hal yang tidak saja terkait dengan masalah penampilan, tapi juga dari beraneka ragam kehidupan, seperti dalam menyikapi sesuatu, dalam berorganisasi, sikap individu dalam sebuah kejadian, ataupun di keluarga sendiri dalam pola asuh anak. Hal yang dialami oleh Ibu Heny berbeda dengan kasus sebelumnya. Dia merasa malu, karena melihat perilaku anaknya yang pemalu, yang selalu ingin terus-menerus berada dekat dengan orang tuanya, menyembunyikan diri di balik baju ibunya, tidak mau diajak berbicara dengan orang asing dan tidak mau melakukan kontak mata (www.epsikologi.com).

Malu untuk bertemu dengan orang asing merupakan prediktor yang paling besar dalam gangguan avoidant personality. Hal ini pernah diteliti pada pasien yang memiliki social phobia (Marteinsdottir et. al., 2003). Rasa malu bertemu dengan orang asing dapat diminimalisasi, berdasarkan penelitian yang dilakukan di Temple, Arizona, ditemukan bahwa kontribusi non verbal orang dewasa dalam rapport yang baik, dapat mengurangi rasa malu. Orang pemalu yang enggan tersenyum jadi mau tersenyum, dan rasa cemasnya berkurang. Pada orang yang pemalu, hal ini sangat membantu perkembangannya dalam menyikapi sesuatu, perilaku non verbal, dan persepsinya saat menghadapi orang asing (Rotenberg et. al., 2003).

Individu yang pemalu biasanya berperilaku suka menghindar dan pasif, aversif, ketakutan, bicaranya pelan, sulit mengekspresikan diri, bicara tidak lancar, dan cemas. Ada beberapa faktor yang menyebabkan seseorang menjadi pemalu, yaitu kondisi yang asing, situasi yang formal, mendapat perhatian sosial yang berlebihan atau bahkan tidak mendapat perhatian, dan privacy-nya dilanggar (McCroskey \& Daily, 1984).

Dalam menghadapi masalah pada situasi yang baru, individu yang pemalu cenderung untuk menghindar ke tempat yang menurutnya lebih nyaman. Selain menghindari tempat yang baru, mereka juga menghindari kontak dengan orang asing. Sesering apapun seseorang menghindar, namun tidak bisa tidak berkomunikasi dengan orang lain, karena manusia adalah makhluk sosial yang membutuhkan orang lain, selain itu kurangnya komunikasi antara individu akan menghambat perkembangan kepribadian seseorang (Rakhmat, 2005).

Para ahli berpendapat bahwa rasa malu dapat diatasi dengan memberikan treatment (perlakuan). Pada Klinik Shyness yang dikepalai Zimbardo, rasa malu dapat diatasi dengan pelatihan komunikasi. Komunikasi merupakan 
media dalam berperilaku. Semua perilaku mempunyai sebuah pesan, walaupun itu hanya sekedar tersenyum, tanpa harus menggunakan kata-kata. Isyarat tubuh merupakan bentuk pesan tersendiri dalam berkomunikasi dengan orang lain. Namun, sebuah isyarat tidak akan berdampak lebih jauh dalam interaksi, tanpa adanya komunikasi verbal dengan orang lain (Supratiknya, 1995).

Komunikasi amatlah penting dalam membina hubungan dengan orang lain, karena dapat memberikan informasi baru dan wacana yang berbeda dalam diri kita. Berkomunikasi dengan orang lain atau komunikasi interpersonal akan menunjang kelangsungan sebuah hubungan yang dinamis dan beragam. Komunikasi antarpribadi atau interpersonal adalah komunikasi antara orang-orang secara bertatap muka, yang memungkinkan setiap pesertanya menangkap reaksi orang lain secara langsung, baik secara verbal ataupun nonverbal (Rakhmat, 2005). Namun, komunikasi merupakan hambatan yang terbesar pada orang yang pemalu, sehingga perlu untuk dilatih. Sebuah bentuk pembelajaran dan pelatihan tentang komunikasi interpersonal akan sangat membantu dalam proses komunikasi interpersonal orang yang pemalu.

Oleh karena itu penelitian ini dilakukan untuk menguji efektivitas pelatihan komunikasi interpersonal dalam mengurangi perasaan malu. Hipotesis yang diajukan adalah pelatihan komunikasi interpersonal dapat mengurangi perasaan malu. Perasaan malu individu akan berkurang setelah mengikuti pelatihan komunikasi interpersonal.

\section{METODE PENELITIAN}

\section{Subjek Penelitian}

Subjek penelitian ini terdiri atas 12 mahasiswa. Enam orang dalam kelompok eksperimen dan enam orang dalam kelompok kontrol. Kelompok eksperimen terdiri dari empat orang laki-laki dan dua orang wanita. Kelompok kontrol terdiri dari lima orang laki-laki dan satu orang wanita. Nomor genap adalah kelompok kontrol, sedangkan nomor ganjil adalah kelompok eksperimen. Pembagian kelompok didasarkan pada nomor urut pendaftaran

Untuk menentukan subjek, peneliti menggunakan metode randomisasi, yaitu random ordering, pemilihan sampel atas dasar urutan nomor unit sampling (Latipun, 2004). Subjek didapatkan melalui pamflet pengumuman pelatihan untuk mengurangi rasa malu. Karakteristik subjek penelitian yakni sebagai berikut :

1. Mahasiswa yang berusia 19 sampai 25 tahun.

2. Berdomisili di Yogyakarta.

3. Ingin mengikuti pelatihan tanpa paksaan.

4. Belum menikah. 


\section{Desain Penelitian}

Penelitian ini menggunakan rancangan penelitian eksperimental murni (true experimental design) dengan desain pretest-posttest control group design. Pelatihan ini ada dua kelompok, ada pelatihan komunikasi interpersonal untuk kelompok eksperimen, dan pelatihan berpikir positif untuk kelompok kontrol. Menggunakan pelatihan berpikir positif bertujuan sebagai placebo agar tidak ada kecemburuan dan perbedaan yang terlalu mencolok antara kelompok kontrol dan kelompok eksperimen (Latipun, 2004). Pelatihan ini disampaikan oleh Team Work yang berasal dari gabungan mahasiswa psikologi dan komunitas Mapapleh. Aspek komunikasi interpersonal yang digunakan adalah kontak, keterlibatan, dan keakraban. Pelatihan ini disampaikan dalam bentuk penyampaian materi, praktek, dan rapling. Pelatihan ini dilakukan selama 3 hari 2 malam.

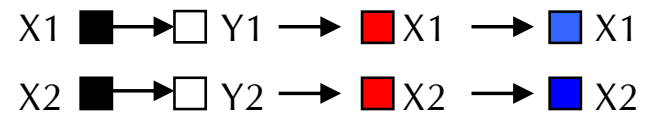

Gambar 1. Desain eksperimen

Keterangan :

X1 : Kelompok Eksperimen

X2 : Kelompok Kontrol

Y1 : Pelatihan Komunikasi Interpersonal

Y2 : Pelatihan Berpikir positif

: Prates

$\square$ : Pascates

口 : Follow Up Test (setelah 4 minggu pelatihan)

\section{Pengumpulan Data}

Pengumpulan data menggunakan alat ukur berupa skala shyness atau rasa malu. Skala shyness diberikan sebelum pelatihan, setelah pelatihan, dan empat minggu setelah pelatihan. Skala shyness adalah skala yang berisi aitem-aitem yang digunakan untuk mengungkap rasa malu. Peneliti membuat skala shyness berdasarkan symptom-symptom shyness yang telah dikemukakan oleh Henderson dan Zimbardo (1998). Skala shyness merupakan gabungan dari beberapa symptom, yaitu :

1. Gejala behavioral meliputi sikap menghindar (inhibition) dan bersikap pasif, gaze aversion, menghindari situasi yang menakutkan, nada bicara rendah, adakalanya badan sedikit bergetar, kurang lancar dalam berbicara, cemas terhadap lingkungan baru, sehingga sering bereaksi seperti memegang hidung, wajah, mengelinting rambut.

2. Gejala-gejala shyness secara physiological meliputi jantung berdebardebar, mulut kering, menggigil dan mengalami goncangan, berkeringat, merasa pusing, mau pingsan, sakit perut, dan takut kehilangan kontrol.

3. Gejala-gejala shyness secara kognitif adalah berpikir negatif tentang diri dan situasi baru, takut dinilai secara negatif dan terlihat tolol di mata orang lain, khawatir dan berusaha untuk bersikap sesempurna mungkin, berkeyakinan negatif tentang kemampuan diri tanpa 
disadari, menyalahkan diri setelah berhubungan sosial, memiliki konsep diri yang negatif.

4. Gejala-gejala shyness secara afeksi adalah shame, harga diri rendah, penuh dengan kesedihan dan penyesalan, merasa kesepian, dan selalu gelisah.

Berdasarkan aspek-aspek di atas, dilakukan pembuatan aitem-aitem skala shyness. Item-item diuji coba. Data yang diperoleh melalui tahap uji coba alat ukur selanjutnya dilakukan uji validitas dan uji realibilitas. Perhitungan untuk menguji validitas dan reabilitas terhadap skala shyness dilakukan dengan fasilitas komputer program Software Statistical Product and Service Solution (SPSS) 12 for Windows.Validitas skala dan seleksi aitem dalam penelitian menggunakan parameter indeks daya beda aitem 0,3 Item yang kurang ari 0,3 dinyatakan gugur (Wahana Komputer, 2005). Koefisien validitas aitem yang valid atau sahih bergerak dari 0,3731 sampai dengan 0,7453 . Skala shyness terdiri atas 48 aitem. Skala yang gugur sebanyak 14 aitem, dan yang terpilih sebanyak 34 aitem. Aitemaitem tersebut telah memenuhi kriteria validitas dan mencangkup keseluruhan aspek yang hendak diungkapkan. Uji reabilitas skala shyness dikenakan pada aitem-aitem yang telah memenuhi syarat validitas. Uji reabilitas menggunakan teknik korelasi Alpha Cronbach pada SPSS 12 for Windows. Uji reabilitas terhadap skala shyness menghasilkan koefisien Alpha sebesar 0,9008. Dengan demikian, skala shyness dapat dikatakan reliabel, sehingga memenuhi syarat untuk dipergunakan sebagai alat ukur untuk pengambilan data dalam penelitian ini.

\section{Intervensi}

Intervensi yang diberikan dalam penelitian adalah training komunikasi interpersonal. Intervensi diberikan pada subjek sebelum, ketika, dan setelah pelatihan. Prosedur penelitian ini adalah :

1. Menempelkan pamflet yang berisi waktu pelaksanaan briefing, tes, pelatihan dan karakteristik subjek penelitian. Karakteristik subjek penelitian yaitu mahasiswa yang berusia 19 sampai 25 tahun, berdomisili di Yogyakarta, ingin mengikuti pelatihan tanpa paksaan, dan belum menikah.

2. Subjek yang tertarik dan sesuai dengan karakteristik dalam pamflet, menghubungi peneliti dan melakukan briefing untuk mengetahui prosedur pelaksanaan pelatihan. Setelah ketentuan disepakati, subjek mengisi lembar partisipasi dan mengerjakan prates. Data subjek dibagi menjadi kelompok eksperimen dan kelompok kontrol, berdasarkan nomor urut pendaftaran. Nomor genap adalah kelompok kontrol, sedangkan nomor ganjil adalah kelompok eksperimen.

3. Pada tanggal pelaksanaan, subjek berkumpul di boulevard Universitas Islam Indonesia untuk pergi bersamasama ke lokasi pelatihan di Sapu Angin. Setelah sampai, lalu mendiri- 
kan tenda, pembagian kelompok, istirahat, sholat, dan makan. Setelah itu sesi I simulasi perkenalan kelompok, yang bertujuan untuk menumbuhkan suasana yang kondusif selama pelatihan berlangsung, saling percaya, nyaman, dan aman secara fisik dan psikis, membagi kelompok, mengenal peserta yang lain, setelah itu lalu tidur.

4. Pada hari kedua, subjek masak sendiri, sholat, dan makan. Pelatihan dimulai dengan sesi II tentang pengarahan navigasi, agar peserta mengetahui cara membaca dan menggunakan kompas sebagai penunjuk arah. Setelah peserta paham bagaimana membaca arah, kemudian sesi III sampai sesi VI diberikan, karena sesi III sampai dengan sesi VI berada di pos-pos yang telah ditentukan.

5. Pada sesi III, peserta menerima materi tentang pesan verbal, yang bertujuan agar peserta menyadari penting komunikasi dan persamaan persepsi, peserta mengetahui hambatan-hambatan dalam berkomunikasi, dan peserta terlatih keberaniannya untuk berbicara dengan orang lain. Sesi $\mathrm{IV}$, yang berisi tentang pesan non verbal, bertujuan agar peserta dapat mengungkapkan perasaan, membaca ekspresi wajah orang lain, dan pentingnya persamaan persepsi, dan peserta dapat mengutarakan harapan, keinginan. Sesi $\mathrm{V}$, yang berisi tentang teknik mendengarkan, bertujuan agar peserta dapat mendengarkan dengan baik dan sabar, dan peserta dapat belajar terbuka pada orang lain. Sesi VI, yang berisi proses hubungan manusia, bertujuan agar peserta mampu mengetahui hambatan yang biasa terjadi dalam hubungan, peserta tahu bagaimana memecahkan solusi bila ada miscommunication, peserta dapat belajar menerima masukan dan kritikan, dan peserta berani mengemukakan pendapat.

6. Setelah perjalanan ke pos-pos, dilakukan sesi VII berupa ice breaking, yang bertujuan agar peserta tahu sikap apa yang harus diubah dan tahu solusinya. Setelah itu subjek istirahat, makan, lalu dilakukan sesi VIII, yaitu pentas seni, agar menumbuhkan rasa percaya diri, peserta belajar menghadapi orang banyak, peserta dapat mengungkapkan perasaan, isi hati, dan terbuka, dan peserta dapat akrab dengan orang lain. Setelah sesi VIII, peserta tidur.

7. Pada hari ketiga, peserta istirahat, makan, melakukan senam peregangan untuk menghadapi sesi IX, lalu baru mengikuti sesi IX, yaitu rapling, yang bertujuan agar peserta belajar menghadapi rasa takut, dan dapat belajar mempercayai orang lain yang baru dikenal. 


\section{Metode Analisis Data}

Data yang diperoleh adalah data kuantitatif. Metode analisis data digunakan untuk menguji hipotesis penelitian ini adalah teknik analisis uji U-Mann Whitney test dan teknik analisis Uji Tanda-The Sign Test. Untuk menjaga keakuratan dan kemudahan pengolahan data digunakan teknik perhitungan data melalui program Software Statistical Product and Service Solution (SPSS) 12 for Windows.

\section{HASIL PENELITIAN}

\section{Deskripsi data penelitian}

1. Prates kelompok eksperimen dan kelompok kontrol

Tabel 1. Deskripsi prates kelompok eksperimen dan kelompok kontrol

\begin{tabular}{lrrrrr}
\hline & N & Minimum & Maximum & Mean & Std. Deviation \\
\hline Preeks eksperimen & 6 & 76,00 & 99,00 & 86,8333 & 8,06019 \\
Prekon control & 6 & 48,00 & 82,00 & 70,5000 & 13,76590 \\
Valid N (listwise) & 6 & & & & \\
\hline
\end{tabular}

\section{Keterangan:}

Preeks : Prates Kelompok eksperimen

Prekon : Prates Kelompok kontrol

$\mathrm{N} \quad$ : Jumlah subjek

Tabel 1. menunjukkan prates kelom- terendah 76 dan skor tertinggi 99. Ratapok kontrol dengan subyek 6 orang, rata untuk kelompok eksperimen, yaitu memperoleh skor terendah 48 dan skor 86,8333 dan standar deviasi 8,06019. tertinggi sejumlah 82. Kelompok kontrol Dengan demikian, dapat disimpulkan memiliki skor rata-rata sebesar 70,5 dan skor prates kelompok eksperimen lebih standar deviasi 13,7659. Prates untuk tinggi dibandingkan dengan kelompok kelompok eksperimen dengan jumlah kontrol.

subyek yakni 6 orang memiliki skor 
2. Pascates kelompok eksperimen dan kelompok kontrol

Tabel 2. Deskripsi Pascates kelompok eksperimen dan kelompok kontrol.

\begin{tabular}{llrrrr}
\hline & N & Minimum & Maximum & Mean & Std. Deviation \\
\hline Pascateks & 6 & 72,00 & 90,00 & 80,1667 & 5,94699 \\
Pascakon & 6 & 45,00 & 86,00 & 72,5000 & 14,67992 \\
Valid N (listwise) & 6 & & & & \\
\hline
\end{tabular}

\section{Keterangan:}

Pascateks : Pascates kelompok eksperimen

Pascakon : Pascates kelompok kontrol

$\mathrm{N} \quad$ : Jumlah subjek

Tabel 2 menunjukkan pascates terendah 72 dan skor tertinggi 90. Ratakelompok kontrol dengan subyek 6 orang, rata untuk kelompok eksperimen, yaitu memperoleh skor terendah 45 dan skor 80,1667 dan standar deviasi 5,94699. tertinggi sejumlah 86. Kelompok kontrol Dengan demikian, dapat disimpulkan memiliki skor rata-rata sebesar 72,5 dan skor pascates kelompok eksperimen lebih standar deviasi 14,67992. Prates untuk tinggi dibandingkan dengan kelompok kelompok eksperimen dengan jumlah kontrol. subyek yakni 6 orang memiliki skor

3. Gains score kelompok eksperimen dan kelompok kontrol

Tabel 3. Deskripsi Gains Score kelompok eksperimen dan kelompok kontrol

\begin{tabular}{llrrrr}
\hline & N & Minimum & Maximum & Mean & Std. Deviation \\
\hline Gainseks & 6 & $-21,00$ & $-2,00$ & $-6,6667$ & 7,14609 \\
Gainskon & 6 & $-3,00$ & 9,00 & 2,0000 & 4,09878 \\
Valid (listwise) & 6 & & & & \\
\hline
\end{tabular}

\section{Keterangan:}

Gainseks : Gains Score kelompok eksperimen

Gainskon : Gains Score kelompok kontrol

$\mathrm{N} \quad$ : Jumlah subjek 
Tabel 3 menunjukkan Gains Score kelompok kontrol dengan subyek 6 orang, memperoleh skor terendah -3 dan skor tertinggi sejumlah 9. Kelompok kontrol memiliki skor rata-rata sebesar 2 dan standar deviasi 4,09878. Gains Score untuk kelompok eksperimen dengan jumlah subyek yakni 6 orang memiliki skor terendah -21 dan skor tertinggi -2. Rata-rata untuk kelompok eksperimen, yaitu $-6,6667$ dan standar deviasi 7,14609. Dengan demikian, dapat disimpulkan gains score kelompok kontrol lebih tinggi dibandingkan dengan kelompok eksperimen.

Tabel deskripsi di bawah ini, merupakan gambaran umum data penelitian yang dituliskan secara singkat :

Tabel 4. Deskripsi Data Penelitian

\begin{tabular}{ccccccccc}
\hline \multirow{2}{*}{ variabel } & \multicolumn{3}{c}{ Skor yang diperoleh (empirik) } & \multicolumn{4}{c}{ Skor yang dimungkinkan (hipotetik) } \\
\cline { 2 - 9 } & Min & Max & Mean & SD & Min & Max & Mean & SD \\
\hline shyness & 48 & 99 & 78,6667 & 13,72677 & 34 & 136 & 85 & 17 \\
\hline
\end{tabular}

\section{Keterangan:}

Min : nilai minimum

Max : nilai maksimum

$$
\begin{array}{ll}
\text { Mean } & \text { : nilai rata-rata } \\
\text { SD } & \text { : standar deviasi }
\end{array}
$$

Tabel 4 menunjukkan deskripsi data penelitian dengan skor yang diperoleh untuk variabel shyness. Skor hipotetik minimum adalah 34, dengan skor hipotetik maksimum adalah 136, dan mean hipotetiknya adalah 85, dengan standar deviasi 17.

\section{Hasil Uji Hipotesis}

Ada perbedaan rasa malu (shyness) kelompok eksperimen dan kelompok kontrol setelah mendapat pelatihan. Rasa malu (shyness) kelompok eksperimen lebih rendah daripada kelompok kontrol. Hipotesis I diuji dengan menggunakan analisis U-Mann Whitney test, gain score diperoleh skor $Z=-2.656$ dan skor $p$ sebesar 0,008 (2-tailed)/ 0.004 (1-tailed). Dengan demikian, skor $p<0,01$. Hal ini menunjukkan adanya pengaruh yang sangat signifikan setelah pelatihan. Berdasarkan hasil analisis di atas, maka hipotesis penelitian yang berbunyi ada perbedaan rasa malu (shyness) kelompok eksperimen dan kelompok kontrol setelah mendapat pelatihan dapat diterima. Hipotesis penelitian yang berbunyi rasa malu (shyness) kelompok eksperimen lebih rendah daripada kelompok kontrol dapat diterima. 


\section{PEMBAHASAN}

Tujuan penelitian ini untuk mengetahui efektivitas pelatihan komunikasi interpersonal untuk mengurangi rasa malu (shyness). Berdasarkan analisis data yang ada didapatkan simpulan bahwa hipotesis dari penelitian ini diterima, yaitu ada perbedaan rasa malu (shyness) kelompok eksperimen dan kelompok kontrol setelah mendapat pelatihan. Hal ini menandakan bahwa pelatihan memberikan efek dalam mengurangi rasa malu. Peneliti kemudian mengadakan tes kembali (follow up) setelah 4 minggu dari waktu pelatihan. Sebagai follow up dari pelatihan, dilakukan tes yang bertujuan untuk mengetahui seberapa jauh keefektifan sebuah pelatihan dalam mengurangi rasa malu subjek.

Dari hasil analisis U-Mann Whitney test, didapatkan bahwa tidak adanya perbedaan antara follow up dan sesudah pelatihan pada kelompok eksperimen. Hal ini menunjukkan bahwa dalam rentang waktu selama 4 minggu, subjek tidak mengalami perubahan apapun. Namun, jumlah subjek yang memiliki kategori sedang menjadi $100 \%$, naik dari hasil sesudah pelatihan sebanyak $16,7 \%$. Jadi, walaupun tidak ada perbedaan, namun ada sedikit perubahan kategori subjek dari yang memiliki rasa malu yang rendah menjadi sedang.

Dari penelitian tambahan yang dilakukan, ada beberapa hal yang menyebabkan individu tidak mengalami perubahan dalam rasa malu, yaitu adanya pengaruh internal secara psikologis dan fisik, serta pengaruh eksternal. Pengaruh secara psikologis yang ditemukan dalam penelitian ini adalah adanya subjek merasa kebingungan untuk mendapatkan kebahagiaan dan tidak tahu jalannya, ada juga yang tidak tahu bagaimana cara mengaplikasikan ide, timbulnya rasa malas yang berlebihan karena kurangnya aktivitas, dan adanya rasa takut dalam mengungkapkan perasaan cintanya. Pengaruh internal secara fisik yang ditemukan dalam penelitian ini adalah kondisi yang tidak fit ketika mengikuti pelatihan dan kegiatan setelah pelatihan yang menguras tenaga, karena harus bolak-balik antara satu kota ke kota lain, karena ada urusan keluarga dan masalah sekolah.

Pengaruh eksternal yang timbul terjadi dari lingkungan sosial dan keluarga. Dalam lingkungan sosial, ada subjek yang ingin mengetahui bagaimana memengaruhi orang lain, sehingga dalam pergaulan bisa menjadi panutan, sedangkan subjek lain ada yang memiliki masalah eksternal dari keluarga, karena dia menjadi tumpuan keluarga dan harus berusaha untuk menghasilkan sesuatu, walaupun subjek bingung untuk mengaplikasikan idenya.

Hal yang terjadi dalam penelitian ini, berkaitan erat dengan proses pembelajaran. Pelatihan merupakan proses pembelajaran untuk dapat berubah dan lebih baik, namun sebuah pembelajaran dapat menjadi tidak efektif apabila ada 
seorang pembelajar memiliki masalah yang sama atau masalah yang baru setelah pelatihan (di luar area pelatihan) (Leslie,2005).

Tingkat rasa malu kelompok eksperimen dan kontrol pada awal pelatihan berada dalam base line yang sama, yaitu sedang. Namun, walaupun memiliki baseline yang sama, dari hasil penelitian, kelompok eksperimen dan kelompok kontrol memiliki perbedaan. Kelompok kontrol tidak mengalami perubahan kategori, sedangkan kelompok eksperimen meng-alami perubahan yang lebih baik. Data dalam penelitian menunjukkan bahwa kelompok eksperimen mengalami perubahan, karena hasil tes sebelum pelatihan dan sesudah pelatihan kelompok eksperimen berbeda. Sedangkan kelompok kontrol hasil tes sebelum dan sesudah pelatihan sama, tidak ada perbedaan. Hal ini menunjukkan bahwa pelatihan komunikasi interpersonal memberikan pengaruh dalam mengurangi rasa malu pada kelompok eksperimen, sedangkan pelatihan berpikir positif tidak memberikan pengaruh dalam mengurangi rasa malu pada kelompok kontrol.

Adanya pengaruh pelatihan komunikasi interpersonal terjadi akibat adanya komunikasi antara seorang komunikator dengan komunikan. Pada komunikasi ini komunikator tahu tentang pasti apakah pesannya diterima atau tidak, dan mengetahui alasan komunikan bila tidak menerimanya. Pesan yang disampaikan secara langsung, dan timbal balik, dapat membuat komunikator dan komunikan mengerti maksud dari isi pesan tersebut. Hal ini dapat menimbulkan memungkinkan adanya perubahan dalam sikap, pendapat, bahkan perilaku manusia (Liliweri,1997). Hal ini pula yang menimbulkan adanya perubahan rasa malu seseorang berkurang, karena adanya interaksi tanpa adanya kesalahpahaman dari maksud pesan dan wacana pun bertambah karena adanya rasa untuk membuka diri.

Komunikasi antarpribadi atau interpersonal adalah komunikasi antara orang-orang secara bertatap muka, yang memungkinkan setiap pesertanya menangkap reaksi orang lain secara langsung, baik secara verbal ataupun nonverbal (Rakhmat, 2005). Bentuk khusus dari komunikasi interpersonal adalah komunikasi diadik, yang hanya melibatkan dua orang. Ciri-ciri komunikasi diadik adalah pihak-pihak yang sedang berkomunikasi berada dalam jarak yang dekat. Kedekatan hubungan dapat dilihat dari jenis-jenis pesan atau respons nonverbal mereka, seperti sentuhan, tatapan mata, dan jarak fisik yang sangat dekat. Hal ini terjadi karena lokasi pelatihan antara kelompok eksperimen dan kelompok kontrol adalah sama, namun mendapatkan perlakuan yang berbeda ketika pelatian.

Kelemahan penelitian ini adalah kurangnya koordinasi antara beberapa pihak yang terkait, sehingga ada beberapa acara yang tidak sesuai dengan jadwal 
dan rencananya berakhir siang hari, menjadi sore hari

Selain masalah koordinasi, peneliti juga kurang memperhatikan variabel kontrol. Variabel kontrol sangat penting dalam eksperimen, agar hasil pelatihan benar-benar disebabkan variabel bebas. Varibel yang kurang terkontrol misalnya mood peserta, kesehatan peserta, pengalaman dalam mengikuti pelatihan, kecenderungan peserta untuk cepat dalam beradaptasi dengan lingkungan baru.

\section{PENUTUP}

\section{Simpulan}

Dari hasil penelitian diketahui, pelatihan komunikasi interpersonal dapat secara afektif mengurangi rasa malu, tapi dari hasil follow up (4 minggu setelah pelatihan), pelatihan itu tidak memberikan dampak yang berarti. Hal ini di sebabkan adanya berbagai permasalahan dari faktor internal dan eksternal. Faktor internal di antaranya adanya fluktuasi emosional, pencarian jati diri dan tujuan hidup. Sedangkan faktor eksternal diantaranya berasal dari permasalahan keluarga dan tekanan sosial.

\section{Saran}

Penelitian selanjutnya diharapkan lebih memperhatikan kelompok kontrol, juga dalam wawancara yang mendalam setelah pelatihan, karena hasil secara kuantitatif dapat dibantu dengan adanya wawancara dan observasi.

\section{DAFTAR PUSTAKA}

Drever, J. (1986). Kamus Psikologi. Jakarta: PT. Bina Aksara.

Fordham, K. \& Stevenson-Hinde, J. (1999). Shyness, Friendship Quality, and Adjustment During Middle Childhood. Journal of Child Psychology and Psychiatry. 40 (5), 757-768.

Hall, C.S \& Lindzey, G. (1993). Teori-teori Psikodinamik (Klinis). Yogyakarta: Penerbit Kanisius.

Henderson, L. \& Zimbardo, P. (1998). Shyness. In H.S. Friedman (ed.), Encyclopedia of Mental Health. San Diego,CA: Academic Press

Latipun. (2004). Psikologi Eksperimen, edisi kedua. Malang: UMM Press

Leslie, R. (2005). Melibatkan Pembelajaran Secara Aktif Dalam Pendidikan dan Pelatihan. Jakarta: P.T Gramedia.

Liliweri, A.M.S.(1997).Komunikasi Antarpribadi. Yogyakarta: Penerbit Kanisius.

Marteinsdottir, I., Tillfors, M., Furmark, T., Anderberg, U.M., \& Ekselius, L. (2003). Personality dimension measured by the Temperament and Character Inventory (TCl) in subjects with social phobia. Social Phobia and personality dimensions. Nord Journal Psychiatry, 57(1), 29-35. 
McCroskey, J.A. \& Daily, J. (1984). Avoiding Communication. Shyness, Reticence, and Communication Apprehension. London: Sage Publication.

Monks, F.J., Knoers, A.M.P, Haditono, S.R. (2004). Psikologi Perkembangan. Yogyakarta: Gadjah Mada University Press.

Pusat Pembinaan dan Pengembangan Bahasa Departemen Pendidikan dan Kebudayaan. (2008). Kamus Besar Bahasa Indonesia. Jakarta: Balai Pustaka.

Rakhmat, J. (2005). Psikologi Komunikasi. Bandung: Remadja Rosdakarya

Rotenberg, K.J., Eisenberg, N., Cumming, C., Smith, A. Singh, M. \& Terlicher, E. (2003). The contribution of adults nonverbal cues and children's shyness to the development of rapport between adults and preschool children. International Journal of Behavioral Development. 27 (1),21-30. http://www.tandf. co.uk/journals/pp/01650254.html.
Salim, P. \& Salim, Y. (1991). Kamus Bahasa Indonesia Kontemporer. Jakarta: Modern English Press.

Supratiknya, A. (1995). Komunikasi Antarpribadi. Yogyakarta: Penerbit Kanisius.

Zimbardo, P. (1997). Psychological Theories of Shyness. http:/www. cardiff.ac.uk/socsi/shyness/ shypsychology.html

Wahana Komputer. (2005). Pengembangan Analisis Multivariate Dengan SPSS 12. Jakarta: Penerbit Salemba Infotek

htt:/www.e-psikologi.com/anak/200302.htm http:/www.kaltimpost.web.id/berita/index. asp? Berita $=$ Hiburan\&id $=151747$ 